Fourth International Conference on Sustainable Construction Materials and Technologies http://www.claisse.info/Proceedings.htm

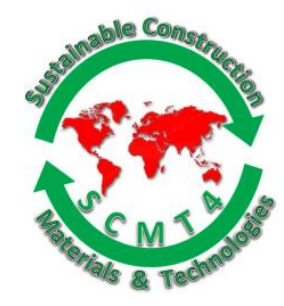

SCMT4

Las Vegas, USA, August 7-11, 2016

\title{
Effect of Paste Volume on Performance of Controlled Low Strength Materials
}

\author{
Vahid Alizadeh ${ }^{1}$ \\ ${ }^{1} 1000$ River road, T-MU1-01, Teaneck, NJ 07666, USA, Fairleigh Dickinson University, \\ Email: 〈alizadeh@fdu.edu>
}

\begin{abstract}
Controlled low strength material (CLSM) is gaining increasing importance with the growing emphasis on sustainability in construction industry. CLSM can be a valuable application for the safe and efficient use of nonstandard materials such as industrial by-products, which are normally rejected for conventional concrete due to the negative impact on hardened properties. In the present study, a laboratory experiment was carried out to explore the effect of paste volume on flowability and strength development of CLSM. The experimental results showed that the paste volume had a more significant effect on the slump flow compared to the water-cementitious material ratio $(w / \mathrm{cm})$; however, it had little effect on compressive strength of CLSM mixtures. It is proposed that the paste volume percentage can be used to target a desired flow in proportioning of CLSM without compromising the compressive strength of the mixtures.
\end{abstract}

\section{INTRODUCTION}

Over the last decades, Controlled low strength material (CLSM) has gained increasing attention in infrastructure applications, which is due, mainly to its intrinsic benefits and widespread applications. CLSM is a highly flowable, self-consolidating construction materials and specified by ACI 229R [2013] with 28-day compressive strength of $8.3 \mathrm{MPa}$ (1200 psi) or less. CLSM contains mostly of fine aggregates, small quantities of cement with large quantities of supplementary cementitious materials, and water.

In actual construction, CLSMs have demonstrated a number of distinct advantages over conventional backfills; it cures rapidly and can flow easily around confined spaces. It is self-leveling, relatively incompressible after curing, durable, and may be easily excavated if desired. CLSM has a number of uses in the construction industry as an alternative to compacted fill including backfill for building excavations, utility trench, and retaining walls; structural fill for footings, road bases and utility bedding; and voidfilling for underground structures [ACI 229R 2013; Alizadeh et al. 2014, Smith 1991]. Although CLSM generally costs more per cubic meter than most soil or granular backfill materials, its many advantages such as reduced labor, self-leveling capability and versatility often result in lower in-place costs [Ramme 1997]. The benefits of CLSM were also imparted efficiently in the rapid construction of bridge abutments. Since it is a self-compacting material, CLSM reduces the volume of labor intensive compacting operation 
needed for the placement of backfills, and therefore, construction of CLSM bridge abutments requires a shorter time compared with conventional bridge abutments [Alizadeh et al. 2014, 2015].

In most applications, CLSM requires less strength than $2.1 \mathrm{MPa}$ (300 psi) to allow for future excavation [ACI 229R 2013]. According to ASTM D4832, CLSM materials have a higher strength than the compacted soil and typical strengths for most applications fall between 350 to $700 \mathrm{kPa}$ (50 to $100 \mathrm{psi}$ ). The low mechanical requirements enable the use of nonstandard materials for the production of CLSM, which are normally rejected for conventional concrete because of their negative impact on hardened properties. Therefore, CLSM can be a valuable application for industrial by-products and wastes as the supplementary cementitious materials and fine aggregate substitutes. With the growing emphasis on sustainability, CLSM offers a viable means to utilize a wide range of industrial by products, which otherwise pose a problem in their safe disposal. However, the nonstandard materials should be tested to assess their effect on CLSM performance [Bouzalakos et al. 2013, Nataraja and Nalanda 2008].

Research interests in CLSM have mostly been focused on the use of various industrial by-products as major or supplementary constituents of the mixture [Sheen et al. 2014]. Fly ash, a by-product of the coal combustion in electric power plants, is a commonly used supplementary cementitious material [Naik et al. 2006]. Other by-products that are being used in CLSM are bottom ash, blast furnace slag, foundry sand, cement kiln dust, recycled concrete aggregate, scrap tire rubber, wood ash, and flue gas desulfurization materials [Achtemichuk et al. 2009, Katz and Kovler 2004, Nataraja and Nalanda 2008, Seddique 2009, Taha et al. 2007]. In these studies, the impact of alternative constituents on the performance of CLSM has been evaluated by adjusting their mass content in the mixture. Nevertheless, since the contents of constituents in a mixture are interrelated, they cannot be adjusted independently without affecting the mixture proportions. As a result, the reported CLSM performance is a combined result of the constituent's properties and the change of mixture proportion, and this weakens comparison of results between different studies.

In this study, a laboratory experiment was carried out to explore the effect of paste volume in the mixture as an independent parameter on CLSM performance in terms of flowability and compressive strength of the mixtures. The effect of ratio of water to cementing materials $(\mathrm{w} / \mathrm{cm})$ and portland cement to cementing materials $(\mathrm{pc} / \mathrm{cm})$ on CLSM performance was also evaluated. The objective is to suggest independent variables which can best define the change in CLSM relevant responses, and enable unbiased interpretation and comparison of the results among different studies. These independent variables can be employed in proportioning of CLSM mixtures to minimize the number of trial batches usually required to achieve the desired requirements for CLSM properties.

\section{EXPERIMENTAL INVESTIGATION}

The CLSM mixtures studied in this paper were composed of fine aggregate, a supplementary cementing material (SCM), cement, and water. The mixtures were proportioned by adjusting relative ratios between constituents including, the paste volume which corresponds to the volumetric ratio of paste (water, SCM, and cement) to the total volume of the mixture, and mass ratios of water to cementing materials $(\mathrm{w} / \mathrm{cm})$ and portland cement to cementing materials $(\mathrm{pc} / \mathrm{cm})$. Experimental studies in CLSM literature include mixtures with paste volumes covering a range of 32\% to 47\% [ACI 229R 2013; Alizadeh et al. 2014, Du et al. 2002, Folliard et al. 2008, Katz and Kovler 2004, Naik et al. 2006, Naganathan et al. 2012, Nataraja and Nalanda 2008, Taha et al. 2007]. For this study, paste volumes of 35\%, 40\% and 45\% was considered. Table 1 shows the experimental cases performed to study the relationship between these relative ratios as independent parameters and CLSM responses in terms of the ability to flow (slump flow), and unconfined compressive strength. For each mixture in Table 1, mass contents of the ingredients were determined 
from the required volumes, considering absolute volume of the whole mixture and according to the specific of gravities of the materials. Water adjustments were made to compensate for the aggregate moisture content.

After mixing the ingredients in a drum mixer, flowability of the fresh mixtures was determined by the slump flow diameter according to ASTM D6103. ACI 229R specifies a flow of at least $200 \mathrm{~mm}(8 \mathrm{in}$.) for CLSM. The specimens then were cast in $100 \times 200 \mathrm{~mm}(4 \times 8$ in. $)$ cylindrical molds and cured at $23^{\circ} \mathrm{C}$ for varying periods, 1-day, 7-day and 28-day, before the compressive strength testing. Because of the self-leveling characteristics of CLSM, casting the cylinder molds did not require densification as is normally needed for concrete samples. Three specimens from each mixture were tested for compressive strength according to the ASTM D4832. Load-controlled unconfined compressive strength test was employed using a relatively low-load capacity computerized testing machine at a constant rate such that the cylinder would fail in not less than $2 \mathrm{~min}$. Unbonded metal caps fitted with elastomeric material pads were used to avoid damage to the specimen surface.

Table 1. Investigated CLSM Mixtures and the Results

\begin{tabular}{|c|c|c|c|c|c|c|c|c|}
\hline Mix & VP\% & w/cm & pc/cm & flow & \multirow{2}{*}{$\begin{array}{c}\text { Density } \\
\left(\mathrm{mg} / \mathrm{m}^{3}\right)\end{array}$} & \multicolumn{3}{|c|}{ Compressive Strength (kPa) } \\
\cline { 7 - 9 } & & & & & 3 days & 7 days & 28 days \\
\hline 1 & $40 \%$ & 0.6 & 0.15 & 231 & 1971 & 315 & 1223 & 2206 \\
\hline 2 & $40 \%$ & 0.8 & 0.15 & 314 & 1897 & 337 & 471 & 1127 \\
\hline 3 & $40 \%$ & 1.0 & 0.15 & 341 & 1827 & 155 & 307 & 672 \\
\hline 4 & $40 \%$ & 1.2 & 0.15 & 372 & 1805 & 112 & 174 & 513 \\
\hline 5 & $45 \%$ & 0.6 & 0.15 & 403 & 1907 & 537 & 1042 & 2005 \\
\hline 6 & $45 \%$ & 0.8 & 0.15 & 506 & 1937 & 291 & 525 & 945 \\
\hline 7 & $45 \%$ & 1 & 0.15 & 556 & 1930 & 178 & 352 & 632 \\
\hline 8 & $35 \%$ & 0.6 & 0.15 & 198 & 2008 & 388 & 707 & 1397 \\
\hline 9 & $35 \%$ & 0.8 & 0.15 & 257 & 1984 & 233 & 352 & 677 \\
\hline 10 & $35 \%$ & 1 & 0.15 & 274 & 1929 & - & - & 443 \\
\hline 11 & $40 \%$ & 0.6 & 0.1 & 240 & 1940 & - & - & 615 \\
\hline 12 & $40 \%$ & 0.8 & 0.1 & 329 & 1893 & - & - & 302 \\
\hline 13 & $40 \%$ & 1 & 0.1 & 353 & 1910 & - & - & 215 \\
\hline 14 & $40 \%$ & 1.2 & 0.1 & 381 & 1921 & - & - & 169 \\
\hline 15 & $40 \%$ & 0.6 & 0 & 238 & 1892 & - & - & 219 \\
\hline 16 & $40 \%$ & 0.8 & 0 & 332 & 1859 & - & - & 172 \\
\hline 17 & $40 \%$ & 1 & 0 & 351 & 1911 & - & - & 138 \\
\hline 18 & $40 \%$ & 1.2 & 0 & 375 & 1891 & - & - & 127 \\
\hline 19 & $40 \%$ & 0.6 & 0.2 & 213 & 2001 & - & - & 3781 \\
\hline 20 & $40 \%$ & 0.8 & 0.2 & 304 & 2035 & - & - & 2310 \\
\hline 21 & $40 \%$ & 1 & 0.2 & 330 & 1759 & - & - & 1552 \\
\hline 22 & $40 \%$ & 1.2 & 0.2 & 362 & 1651 & - & - & 1317 \\
\hline
\end{tabular}

Materials. Ordinary Portland cement, fly ash as a SCM, natural sand as a fine aggregate, and tap water were used for the production of the CLSM mixtures. Physical properties of the constituents are shown in Table 2.

Portland cement conforming to ASTM C150 type I was manufactured by Lafarge Cement and had the following compound composition: $\mathrm{C} 3 \mathrm{~S}-55 \%, \mathrm{C} 2 \mathrm{~S}-17.6 \%, \mathrm{C} 3 \mathrm{~A}-8.0 \%, \mathrm{C} 4 \mathrm{AF}-8.2 \%$ and contained $3.4 \%$ of limestone filler. Class $\mathrm{F}$ fly ash for this research was processed by Separation Technologies under 
the ProAsh brand. Chemical properties of the fly ash is shown in Table 3 and compared with the requirements of ASTM C618 specification. The particle size distribution of the sand which was used as the fine aggregate complies with the ASTM C33 that classifies the fine aggregates for the use in concrete.

Table 2. Physical Properties of Solid Materials

\begin{tabular}{|c|c|c|c|c|c|c|}
\hline & \multicolumn{2}{|c|}{ Specific gravity } & \multirow{2}{*}{$\begin{array}{l}\text { Dry bulk density } \\
\qquad\left(\mathrm{kg} / \mathrm{m}^{3}\right)\end{array}$} & \multirow[t]{2}{*}{ Voids \% } & \multirow{2}{*}{$\begin{array}{l}\text { Absorption } \\
\text { capacity \% }\end{array}$} & \multirow{2}{*}{$\begin{array}{l}\text { Moisture } \\
\text { content \% }\end{array}$} \\
\hline & Dry & SSD & & & & \\
\hline Cement & 3.15 & - & - & - & - & - \\
\hline Fly Ash & 2.65 & - & - & - & - & - \\
\hline Sand & 2.557 & 2.591 & 1726 & 32.5 & 1.32 & 1.1 \\
\hline
\end{tabular}

Note: SSD is saturated surface-dry condition.

Table 3. Chemical Composition of the Fly Ash

\begin{tabular}{|c|c|c|c|c|c|c|c|c|}
\hline & $\mathrm{SiO}_{2}$ & $\mathrm{Al}_{2} \mathrm{O}_{3}$ & $\mathrm{Fe}_{2} \mathrm{O}_{3}$ & $\mathrm{CaO}$ & $\mathrm{MgO}$ & $\mathrm{Na}_{2} \mathrm{O}$ & $\mathrm{K}_{2} \mathrm{O}$ & $\mathrm{SO}_{3}$ \\
\hline Fly ash & $55.3 \%$ & $21.4 \%$ & $10.2 \%$ & $3.4 \%$ & $0.98 \%$ & $0.96 \%$ & $2.11 \%$ & $0.92 \%$ \\
\hline ASTM C618 & & m: $70 \%$ & & & & & & $3 \% \max$ \\
\hline
\end{tabular}

\section{EXPERIMENTAL RESULTS AND DISCUSSION}

A total of 22 CLSM mixtures with different levels of paste volume, w/cm ratio, and $\mathrm{pc} / \mathrm{cm}$ ratio were produced. Table 2 shows slump flow, compressive strength, and density of different CLSM mixtures proportioned in this research study.

Flowabilty. According to Figure 1, paste volume has more significant effect on the CLSM flowability than $w / \mathrm{cm}$. This is due the fact that aggregate is the major constituent of a CLSM mixture, and with increase in paste volume, the volume of aggregate in the mixture decreases, and therefore less amount of water is needed to separate the solid particles and provide mobility among them and increase the fluidity of the mixture. For paste volumes larger than 40\%, all mixtures show a more profound increase in flowability (Figure 1a).

For a fixed paste volume, increase in w/cm provides more slump flow; however, all curves in Figure $1 \mathrm{~b}$ reach a plateau, showing that the effect becomes insignificant at higher w/cm values. Furthermore, the effect of $\mathrm{w} / \mathrm{cm}$ increases as the paste content increases.

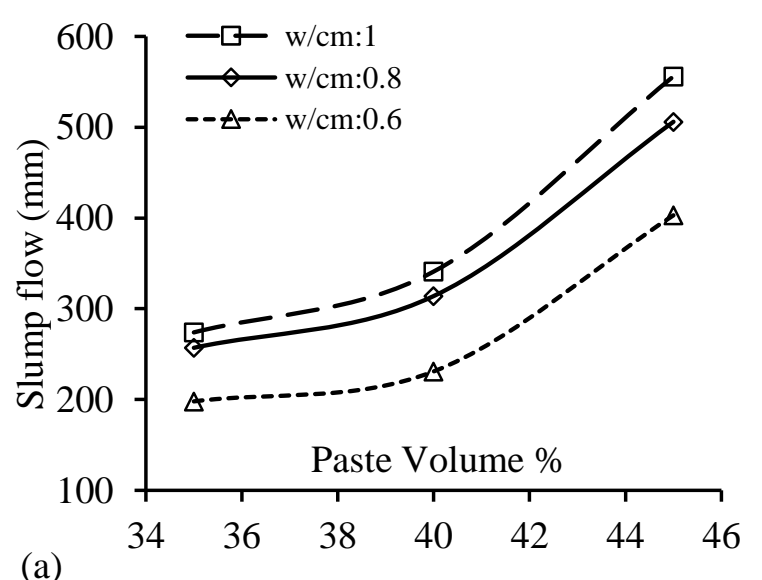

(a)

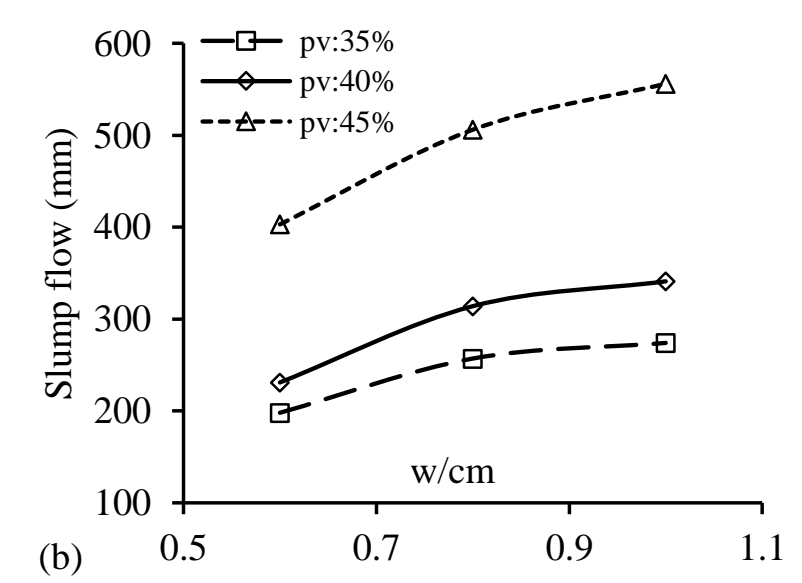

Figure1. Slump Flow as a Function of (a) Paste Volume, and (b) w/cm Ratio 
As shown in Figure 2, for the range in which the ratio of $\mathrm{pc} / \mathrm{cm}$ is studied, it has insignificant effect on the flowability of the CLSM mixtures. Higher contents of portland cement in total cementing materials, reduced the flow slump to some extent.

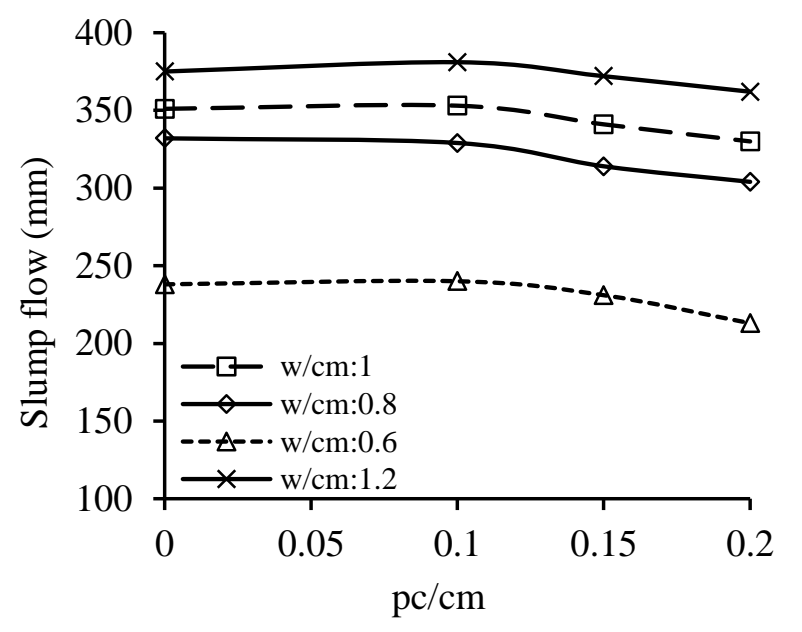

Figure 2. Effect of pc/cm Ratio on Slump Flow

Compressive strength. The 28-day compressive strength of the produced mixtures in Table 2 ranged from a very low strength of $172 \mathrm{kPa}(25 \mathrm{psi})$ for mixtures without portland cement to a relatively higher strength of $3780 \mathrm{kPa}(548 \mathrm{psi}$ ) for mixtures with high portland cement content ( $20 \%$ of total cementing materials). For mixtures with portland cement content of $15 \%$ or less, the 28 -day compressive strength was below the range for excavatability. Figure 3 demonstrates the development of compressive strength with curing age for mixtures with fixed $\mathrm{pc} / \mathrm{cm}$ ratio of 0.15 , and corresponding paste volume and $\mathrm{w} / \mathrm{cm}$ ratio. The average ratio of 3-day to 28-day and 7-day to 28 -day compressive strength of the mixtures is $25 \%$ and $50 \%$, respectively.

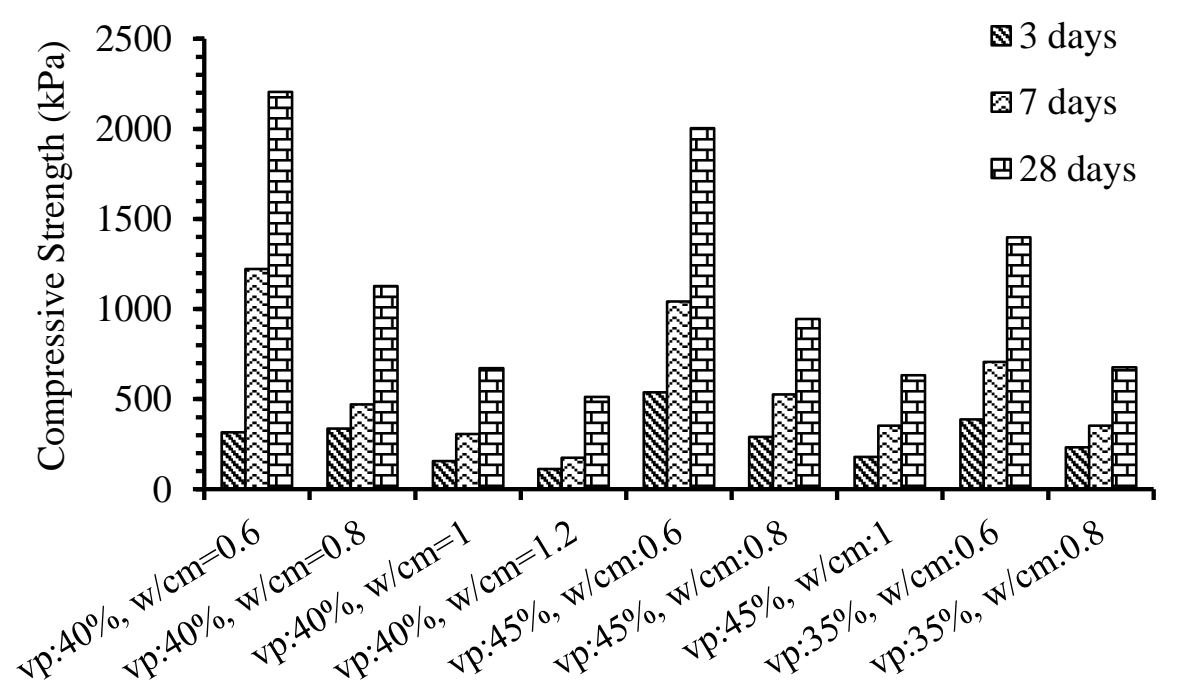

Figure 3. Strength Development of CLSM Mixtures 
Comparing the results in Figures 4, 5, and 6 demonstrates that the pc/cm ratio has the largest effect on compressive strength of the mixtures and paste volume has the smallest. As shown in Figure 4, the effect of paste volume on compressive strength is not significant. Increase in paste volume to $40 \%$, somewhat increased the strength, thereafter compressive strength decreased. It shows that there is an optimum value for the paste volume which provides the highest strength for the mixtures; the optimum paste volume in this study is about $40 \%$. As expected, the compressive strength increased with decreasing w/cm ratio, Figure 5. Likewise, the compressive strength is positively correlated to the pc/cm ratio, Figure 6 . The observed effects of w/cm and $\mathrm{pc} / \mathrm{cm}$ ratios on CLSM compressive strength suggest that $\mathrm{w} / \mathrm{cm}$ needs to be minimized to reduce the required amount of portland cement to achieve a required strength.

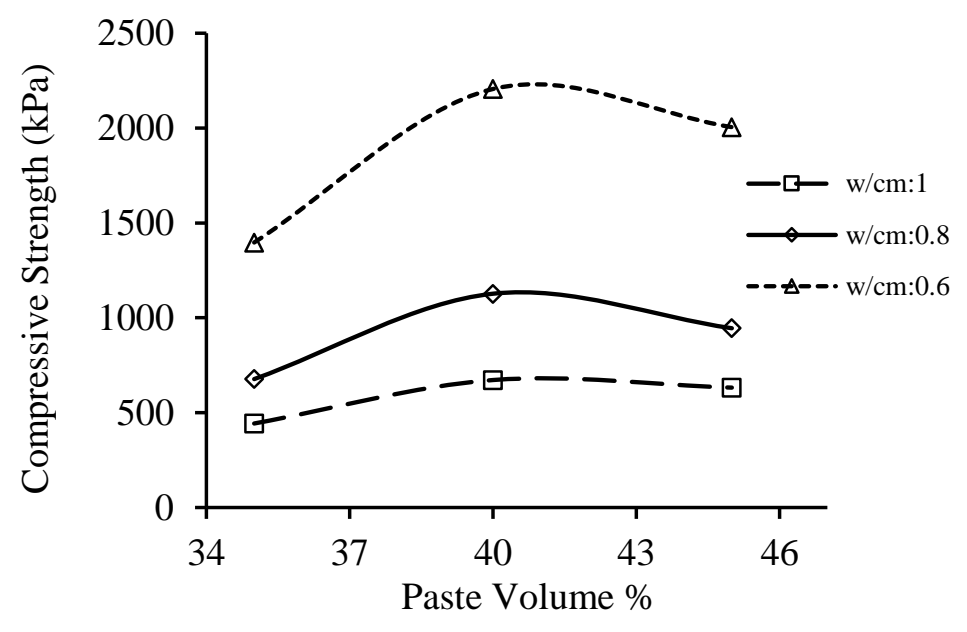

Figure 4. Effect of Paste Volume on Compressive strength
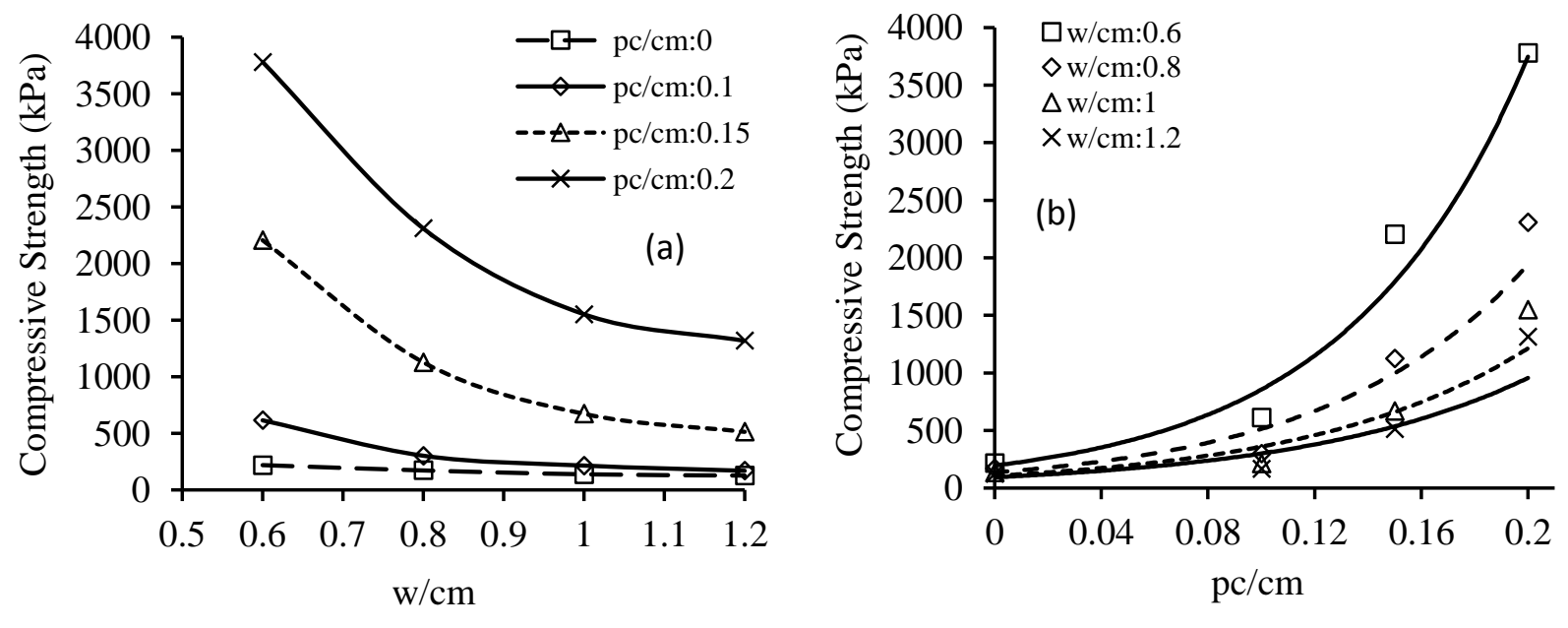

Figure 5. Compressive Strength as a Function of (a) w/cm Ratio, and (b) pc/cm Ratio

\section{CONCLUSION}

A laboratory experiment was carried out to explore the effect of some independent variables on CLSM properties in terms of the flowability and the compressive strength. These variables are relative ratios between the constituent materials of CLSM, including the paste volume to the total volume of the mixture, 
and mass ratios of water to cementing materials $(\mathrm{w} / \mathrm{cm})$ and portland cement to cementing materials $(\mathrm{pc} / \mathrm{cm})$. The following general results were obtained from this study:

- The paste volume was found to have the strongest effect on flowability, but the w/cm ratio had a comparatively low effect. For all mixtures with paste volume larger than $40 \%$, the flow slump increase was substantial. The effect of $\mathrm{pc} / \mathrm{cm}$ ratio on flowability was insignificant.

- The pc/cm ratio had the largest effect on compressive strength of CLSM and paste volume had the smallest. It was found that a paste volume of about $40 \%$ is an optimum value which provides a relatively higher strength.

- It is recommended to decrease the $w / \mathrm{cm}$ in order to achieve a desired strength rather than increasing cement content. The adverse effect of this on flowability can be corrected by adjusting the paste volume to target a desired flow without compromising the compressive strength of the mixtures.

It is concluded that these factors (paste content, $w / \mathrm{cm}$, and $\mathrm{pc} / \mathrm{cm}$ ) can provide adequate control over the relevant properties of CLSM. Hence, they can be employed for the mixture design of CLSM mixtures to minimize the number of trial batches and to enable the unbiased interpretation of the results and comparing findings to other studies.

\section{REFERENCES}

ACI Committee 229. (2013). "229R-13 Report on Controlled Low-Strength Materials." American Concrete Institute, Farmington Hills, MI.

Achtemichuk, S., Hubbard, J., Sluce, R., \& Shehata, M. H. (2009). The utilization of recycled concrete aggregate to produce controlled low-strength materials without using Portland cement. Cement and Concrete Composites, 31(8), 564-569.

Alizadeh, V., Helwany, S., Ghorbanpoor, A., and Oliva, M. (2014). "Rapid-construction technique for bridge abutments using controlled low-strength materials." J. Perform. Constr. Facil., 28(1), 149-156.

Alizadeh, V., Helwany, S., Ghorbanpoor, A., and Sobolev, K. (2014). "Design and application of controlled low strength materials as a structural fill." Construction and Building Materials, 53, 425431.

Alizadeh, V., Helwany, S., Ghorbanpoor, A., Oliva, M., and Ghaderi, R. (2015). "CLSM bridge abutments-Finite element modeling and parametric study. " Computers and Geotechnics, 64, 61-71.

ASTM D4832. (2010). "Standard test method for preparation and testing of controlled low strength material (CLSM) test cylinders." ASTM International, West Conshohocken, PA.

ASTM D6103. (2004). "Standard test method for flow consistency of controlled low strength materials (CLSM)." ASTM International, West Conshohocken, PA.

ASTM C150. (2012). "Standard specification of portland cement." ASTM International, West Conshohocken, PA.

ASTM C33. (2008). "Standard specification for concrete aggregates." ASTM International, West Conshohocken, PA.

ASTM C618. (2015). "Standard specification for coal fly ash and raw or calcined natural pozzolan for use in concrete." ASTM International, West Conshohocken, PA. 
Bouzalakos, S., Dudeney, A. W. L., and Chan, B. K. C. (2013). "Formulating and optimising the compressive strength of controlled low-strength materials containing mine tailings by mixture design and response surface methods." Minerals Engineering, 53, 48-56.

Du, L., Folliard, K. J., \& Trejo, D. (2002). "Effects of constituent materials and quantities on water demand and compressive strength of controlled low-strength material." Journal of materials in civil engineering, 14(6), 485-495.

Folliard, K. J., Du, L., Trejo, D., Halmen, C., Sabol, S., and Leshinsky, D. (2008). "Development of a Recommended Practice for Use of Controlled Low-Strength Material in Highway Construction." NCHRP Report 597, Transportation Research Board, Washington, DC.

Katz, A., and Kovler, K. (2004). "Utilization of industrial by-products for the production of controlled low strength materials (CLSM)". Waste Management, 24(5), 501-512.

Naik, T. R., Kraus, R. N., Ramme, B. W., Chun, Y. M., and Kumar, R. (2006). "High-carbon fly ash in manufacturing conductive CLSM and concrete." Journal of materials in civil engineering, 18(6), 743 746.

Naganathan, S., Razak, H. A., \& Hamid, S. N. A. (2012). "Properties of controlled low-strength material made using industrial waste incineration bottom ash and quarry dust." Materials \& Design, 33, 56-63.

Nataraja, M. C., and Nalanda, Y. (2008). "Performance of industrial by-products in controlled lowstrength materials (CLSM)." Waste management, 28(7), 1168-1181.

Ramme, B. W. (1997). "Progress in CLSM: continuing innovation." Concrete International, 19(5), 3233.

Sheen, Y. N., Huang, L. J., Wang, H. Y., \& Le, D. H. (2014). "Experimental study and strength formulation of soil-based controlled low-strength material containing stainless steel reducing slag." Construction and Building Materials, 54, 1-9.

Siddique, R. (2009). "Utilization of waste materials and by-products in producing controlled low-strength materials." Resources, conservation and recycling, 54(1), 1-8.

Smith, A. (1991). "Controlled low strength materials." Concrete Construction, 389-398.

Taha, R. A., Alnuaimi, A. S., Al-Jabri, K. S., \& Al-Harthy, A. S. (2007). "Evaluation of controlled low strength materials containing industrial by-products." Building and Environment, 42(9), 3366-3372. 